\title{
Trastuzumab combined with doublet or single-agent chemotherapy as first-line therapy for HER2-positive metastatic breast cancer
}

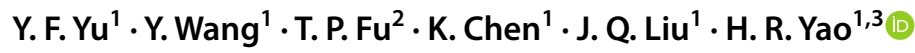

Received: 9 March 2017 / Accepted: 22 November 2017 / Published online: 29 November 2017

(c) The Author(s) 2017. This article is an open access publication

\begin{abstract}
Purpose To investigate the efficacy and safety of doublet versus single-agent chemotherapy (CT) plus trastuzumab (H) as first-line therapy for human epidermal growth factor 2 receptor (HER2)-positive metastatic breast cancer (MBC).

Methods We searched for randomized clinical trials (RCTs) that evaluated the treatment effects of single-agent or doublet $\mathrm{CT}+\mathrm{H}$ as first-line therapies for HER2-positive MBC. The main outcomes measured for this study included the overall response rate (ORR), progression-free survival (PFS), and overall survival (OS). A meta-analysis and trial sequential analysis (TSA) were performed, and the study quality was evaluated using the GRADE framework. The PROSPERO registry number of our analysis is CRD42016043766.

Results The results from four RCTs including 1044 participants were pooled. Moderate-quality evidence indicated that compared with single-agent $\mathrm{CT}+\mathrm{H}$, doublet $\mathrm{CT}+\mathrm{H}$ correlated better with prolonged PFS (hazard ratio [HR] 0.69, 95\% confidence interval $[\mathrm{CI}] 0.63-0.75, P<0.0001)$ and $\mathrm{OS}(\mathrm{HR}=0.90,95 \% \mathrm{CI} 0.88-0.92, P<0.0001)$. However, moderatequality evidence revealed no significant difference between the two regimens regarding the ORR (relative risk $[R R]=1.07$, 95\% CI 0.98-1.17, $P=0.157$ ), which was confirmed by TSA, indicating that the cumulative Z-curve entered the futility area. Moderate-quality evidence indicated that treatment-related grade 3 or 4 toxicities of thrombocytopenia $(\mathrm{RR}=4.08$, $P=0.000)$, nausea/vomiting $(\mathrm{RR}=4.26, P=0.002)$, diarrhea $(\mathrm{RR}=2.81, P=0.002)$, and stomatitis $(\mathrm{RR}=5.02, P=0.003)$ were observed more frequently with doublet $\mathrm{CT}+\mathrm{H}$ than with single-agent $\mathrm{CT}+\mathrm{H}$.

Conclusions Compared with single-agent CT, the combination of doublet CT with trastuzumab as first-line therapy for HER2-positive MBC is associated with longer PFS and OS, but more treatment-related grade 3 or 4 toxicities. Therefore, doublet CT appears to be an appropriate regimen for HER2-positive MBC with a good performance status.
\end{abstract}

Keywords Metastatic breast cancer $\cdot$ HER2-positive $\cdot$ Trastuzumab $\cdot$ Single-agent chemotherapy $\cdot$ Doublet-agent chemotherapy $\cdot$ Meta-analysis

Electronic supplementary material The online version of this article (https://doi.org/10.1007/s10549-017-4592-y) contains supplementary material, which is available to authorized users.

Y. F. Yu, Y. Wang and T. P. Fu have contributed equally to this work and should be considered co-first authors.

H. R. Yao

yaoherui@163.com

1 Guangdong Provincial Key Laboratory of Malignant Tumor Epigenetics and Gene Regulation, Breast Tumor Center, Sun Yat-sen Memorial Hospital, Sun Yat-sen University, No. 33 Yinfeng Road, Haizhu District, Guangzhou, Guangdong 510288, People's Republic of China

2 Department of Surgery, State Key Laboratory of Oncology in South China, Collaborative Innovation Center for Cancer

\section{Introduction}

Human epidermal growth factor receptor 2 (HER2), a transmembrane receptor and member of the tyrosine kinase receptor family, mediates tumor invasion, progression, and

Medicine, Sun Yat-sen University Cancer Center, Guangzhou, Guangdong, People's Republic of China

3 Department of Oncology, Sun Yat-sen Memorial Hospital, Sun Yat-sen University, Guangzhou, Guangdong, People's Republic of China 
metastasis $[1,2]$. HER2 protein overexpression or gene amplification occurs in approximately $20-25 \%$ of patients with metastatic breast cancer (MBC), and is characterized by aggressive tumor growth, a high possibility of recurrence, and decreased survival. Fortunately, the introduction of antiHER 2 therapy has alleviated many of these concerns [3, 4].

Blocking HER2 using antibodies with a high affinity to the extracellular domain of the receptor leads to antibodydependent cell-mediated cytotoxicity (ADCC) and prevents the intracellular kinase domain of the receptor from engaging in signal transduction. This blockade results in inhibition of numerous mitogenic pathways in HER2-overexpressing malignant tumor cells $[5,6]$. Trastuzumab (Herceptin $[\mathrm{H}]$, F. Hoffmann-La Roche Ltd, Basel, Switzerland) is a recombinant, humanized monoclonal antibody that inhibits HER2 signaling, and has been approved by the Food and Drug Administration (FDA) for treatment of HER2-positive MBC [7, 8]. Previous clinical studies have extensively evaluated the use of trastuzumab in MBC, and the results have demonstrated that it significantly increases the survival of patients with HER2-positive MBC. Additionally, a number of studies have shown that trastuzumab inhibits tumor growth, produces a high response rate, and improves patient prognosis when used in combination with chemotherapy (CT) $[9,10]$. Trastuzumab exerts greater activity when used in combination due to enhancement in the blockade of HER2 signaling; thus, the combination of trastuzumab with standard taxaneand platinum-based CT is recommended. These combination therapies provide significant survival benefits to women with HER2-positive MBC [10-12].

The current National Comprehensive Cancer Network (NCCN) guidelines recommend trastuzumab combined with CT as first-line therapy for patients with HER2-positive MBC; however, whether doublet-agent CT is superior to single-agent $\mathrm{CT}$ when combined with trastuzumab remains unknown [13]. Moreover, other relevant guidelines regarding these treatment regimens are lacking. In a randomized phase III trial [14] that examined patients with HER2-positive MBC, the addition of carboplatin to paclitaxel and trastuzumab was associated with a higher overall response rate (ORR) and increased overall survival (OS) compared with those obtained with paclitaxel combined with trastuzumab. In contrast, the BCIRG 007 study [15] indicated that in women with HER2-positive MBC, the addition of carboplatin to docetaxel and trastuzumab did not significantly affect the ORR or OS compared with those obtained with docetaxel plus trastuzumab. To resolve such inconsistencies, a comprehensive, high-quality assessment of the most recent randomized clinical trials (RCTs) examining treatment strategies for patients with HER2-positive MBC is warranted. Thus, the current meta-analysis sought to assess the currently available evidence regarding the effectiveness of single-agent versus doublet $\mathrm{CT}$ when combined with trastuzumab-targeted therapy as first-line therapy for women with HER2-positive MBC.

\section{Methods}

This study was registered with PROSPERO (registration number CRD42016043766). The recommendations in the Cochrane Handbook for Systematic Reviews of Interventions and the guidelines in the PRISMA statement were utilized to design, analyze, and report this meta-analysis $[16,17]$.

\section{Database search and trial selection}

A systematic literature search of the PubMed, EMBASE, and Cochrane Central Register of Controlled Trials databases was performed to identify relevant RCTs published prior to July 2016. The population, intervention, comparison, and outcome (PICO) strategy was used with the following search terms: "trastuzumab," "metastatic breast cancer," "HER2 positive," and "randomized clinical trial." No restrictions were imposed regarding sample size, population, language, publication year, publication type, or publication status. The following criteria were applied: RCTs that compared the efficacy of $\mathrm{H}$ combined with "standard CT" (single-agent or doublet) for patients with HER2-positive MBC and original full-text articles that reported one or more of the following outcomes: ORR, disease control rate (DCR), progressionfree survival (PFS), OS, and safety.

\section{Data extraction}

The following baseline characteristics and outcomes were extracted: trial name (including first author, year of publication, and registry numbers for clinical trials), study design, treatment regimen, recruitment period, number of participants, participant and tumor characteristics, follow-up duration, median response duration, median OS, median PFS, and primary and secondary endpoints.

\section{Statistical analyses}

All efficacy endpoints were subjected to intent-to-treat (ITT) analysis when possible. Dichotomous data were analyzed according to the relative risk (RR) and risk difference (RD), with the number of patients needed to treat to benefit (NNTB) and the number of patients needed to treat to harm (NNTH) represented by $1 / \mathrm{RD}$. The DerSimonian and Laird random effects model [18] was utilized when $I^{2}>50 \%$; otherwise, the Mantel-Haenszel fixed effects model [19] was applied. For time-to-event data, estimated hazard ratios (HRs) were pooled using the inverse-variance method [20]. The median survival was summarized as the median ratio 
(MR). The 95\% confidence interval (CI) was reported for all estimates. $P<0.05$ was considered statistically significant. Potential publication bias was visually evaluated using funnel plots and the Copas selection model [21] and quantified using Begg's [22] and Egger's [23] unweighted regression tests. $P<0.05$ indicated a publication bias. All $P$ values were two-sided. Meta-analysis and trial sequential analysis (TSA) were conducted (Supplementary trial sequential analysis, available online). The evidence quality was evaluated using the GRADE framework (Supplementary evidence quality, available online). To ensure the reliability and accuracy of the results, two authors independently uploaded the data. Statistical analyses were performed using $\mathrm{R}$ version 3.3.2 (R Foundation for Statistical Computing, Vienna, Austria).

\section{Results}

\section{Search strategy, results, and study characteristics}

Altogether, 4575 potential studies were identified using the search criteria. We qualitatively examined each article, which resulted in the selection of four RCTs [14, 15, 24, 25] for inclusion in our meta-analysis (Supplementary Fig. S1, available online). The included trials and patient characteristics are presented in Table 1 . The four RCTs [14, 15, 24, 25] were published between 2006 and 2014 by Robert et al. [14], Wardley et al. (NCT01038466) [24], Valero et al. (NCT00047255) [15], and Baselga et al. (NCT00294996) [25]. In total, 1044 participants were included (median age [range] 52 years [18-83]), with 196-363 participants included per study. Three of the four eligible studies were multicenter and/or international randomized trials that recruited participants from 1998 to 2009. Of the included trials, two trials $[14,15]$ examined the combination of $\mathrm{H}$, taxanes (paclitaxel/docetaxel) and carboplatin; one trial [24] examined the combination of $\mathrm{H}$, a taxane (docetaxel) and capecitabine; and one trial [25] examined the combination of a taxane (paclitaxel), an anthracycline (non-pegylated liposomal doxorubicin) and $\mathrm{H}$ (Supplementary Table S1, available online). The baseline patient and tumor characteristics, including patient performance status, disease involvement, clinicopathological tumor features, and prior therapy regimens, showed similar distributions between the study groups. The data revealed that nearly all (99\%) of the patients had a pretreatment performance status of at least $80 \%$ or less than 2, based on the Karnofsky performance score (KPS) or the Eastern Cooperative Oncology Group performance status (ECOG-PS) score, respectively. All trials were determined to have an unclear or high risk of bias due to insufficient participants and the lack of personnel blinding (Supplementary Figs. S2 and S3, available online).

\section{Efficacy}

\section{ORR did not significantly differ between the groups}

Four trials comprising 1034 total participants were included in the current meta-analysis to estimate the ORR. The pooled ORRs were 66 and $61 \%$ for doublet $\mathrm{CT}+\mathrm{H}$ and single-agent $\mathrm{CT}+\mathrm{H}$, respectively. These results provided moderate-quality evidence indicating that no significant difference existed between the two groups in terms of the ORR $(\mathrm{RR}=1.07$, 95\% CI $0.98-1.17, P=0.157, I^{2}=41.3 \%$; RD $=4 \%, 95 \%$ CI -2 to $10 \%$; Fig. 1a, Table 2). The results of Egger's test $(P=0.955)$, Begg's test $(P=1.000)$, and the Copas selection model indicated that there was no evidence of publication bias (Supplementary Fig. S4A, available online). We also subjected the ORR results to TSA, which provided sufficient and conclusive evidence indicating that no significant difference existed between the groups, and thus, further trials were not required (Fig. 2a).

The median response duration was reported in four trials (1034 participants). The median response of the doublet $\mathrm{CT}+\mathrm{H}$ group ranged from 10.7 to 18.1 months, whereas the median response of the single-agent $\mathrm{CT}+\mathrm{H}$ group ranged from 9.4 to 15.3 months. The pooled results provided moderate-quality evidence indicating that the median response duration was significantly longer in the doublet $\mathrm{CT}+\mathrm{H}$ group than in the single-agent $\mathrm{CT}+\mathrm{H}$ group $(\mathrm{MR}=1.17,95 \% \mathrm{CI}$ $1.10-1.25, P<0.0001, I^{2}=0.0 \%$; Table 2; Supplementary Fig. S5A, available online).

\section{The DCR was not significantly different between the groups}

DCR data were available for three RCTs [14, 15, 24] (671 participants). The pooled DCRs for the doublet $\mathrm{CT}+\mathrm{H}$ and single-agent $\mathrm{CT}+\mathrm{H}$ groups were 92 and 87\%, respectively. The pooled results provided low-quality evidence indicating that no significant difference in the DCR existed between the groups $(\mathrm{RR}=1.05,95 \% \mathrm{CI} 0.96$ to $1.15, P=0.282$, $I^{2}=65.8 \% ; \mathrm{RD}=5 \%, 95 \% \mathrm{CI}-4$ to $13 \%$; Fig. $1 \mathrm{~b}$, Table 2 ). No significant publication bias was identified based on the results of Egger's test $(P=0.541)$, Begg's test $(P=1.000)$, and the Copas selection model (Supplementary Fig. S4B, available online). We also subjected the DCR results to TSA, which indicated that additional trials were not required and were unlikely to alter the outcomes (Fig. 2b).

\section{Doublet $\mathrm{CT}+\mathrm{H}$ was associated with longer PFS}

We performed a pooled analysis of the three trials [14, 24, 25] (771 participants) that reported sufficient PFS data. The median PFS values for the doublet $\mathrm{CT}+\mathrm{H}$ and single-agent $\mathrm{CT}+\mathrm{H}$ groups ranged from 10.7 to 17.9 and from 7.1 to 14.5 months, respectively. The trials provided 
Table 1 Characteristics of the included randomized clinical trials

\begin{tabular}{|c|c|c|c|c|c|c|c|c|}
\hline \multirow{2}{*}{$\begin{array}{l}\text { Characteristics } \\
\begin{array}{c}\text { Clinicaltrials.gov, } \\
\text { number }\end{array}\end{array}$} & \multicolumn{2}{|l|}{ Robert et al. [14] } & \multicolumn{2}{|c|}{$\begin{array}{l}\text { Wardley et al. [24] } \\
\text { CHAT study }\end{array}$} & \multicolumn{2}{|l|}{$\begin{array}{l}\text { Valero et al. [15] } \\
\text { BCIRG } 007\end{array}$} & \multicolumn{2}{|c|}{ Baselga et al. [25] } \\
\hline & \multicolumn{2}{|l|}{ NS } & \multicolumn{2}{|l|}{ NCT01038466 } & \multicolumn{2}{|l|}{ NCT00047255 } & \multicolumn{2}{|c|}{ NCT00294996 } \\
\hline Study design & \multicolumn{2}{|l|}{ RCT, Phase III } & \multicolumn{2}{|l|}{ RCT, Phase II } & \multicolumn{2}{|l|}{ RCT, Phase III } & \multicolumn{2}{|c|}{ RCT, Phase III } \\
\hline Recruitment period & \multicolumn{2}{|l|}{ 1998-2002 } & \multicolumn{2}{|l|}{ 2002-2005 } & \multicolumn{2}{|l|}{ 2001-2004 } & \multicolumn{2}{|l|}{ 2006-2009 } \\
\hline No. of countries & \multicolumn{2}{|l|}{2} & \multicolumn{2}{|l|}{ NS } & \multicolumn{2}{|l|}{13} & \multicolumn{2}{|l|}{12} \\
\hline No. of centers & \multicolumn{2}{|l|}{83} & \multicolumn{2}{|l|}{43} & \multicolumn{2}{|l|}{80} & 83 & \\
\hline Regimen & HPC & HP & HTX & HT & HTC & HT & HPM & HP \\
\hline No. of participants & 98 & 98 & 112 & 110 & 132 & 131 & 181 & 182 \\
\hline $\begin{array}{l}\text { Age (years) } \\
\text { Median (range) }\end{array}$ & $\begin{array}{l}55 \\
(35-81)\end{array}$ & $\begin{array}{l}56 \\
(33-83)\end{array}$ & $\begin{array}{l}53 \\
(24-82)\end{array}$ & $\begin{array}{l}52 \\
(23-78)\end{array}$ & $\begin{array}{l}51 \\
(18-75)\end{array}$ & $\begin{array}{l}52 \\
(18-75)\end{array}$ & $\begin{array}{l}52 \\
(22-79)\end{array}$ & $\begin{array}{l}53 \\
(30-76)\end{array}$ \\
\hline ECOG-PS or KPS, No. & & & & & & & & \\
\hline 0 or 100 & $59(60.2)$ & $60(61.2)$ & $112(100)$ & $110(100)$ & $132(100)$ & $131(100)$ & $113(62.4)$ & $112(61.5)$ \\
\hline 1 or $80-90$ & $35(35.7)$ & $35(35.7)$ & $0(0)$ & $0(0)$ & $0(0)$ & $0(0)$ & 68 (37.6) & $70(38.5)$ \\
\hline 2 or $<80$ & $4(4.1)$ & $3(3.1)$ & $0(0)$ & $0(0)$ & $0(0)$ & $0(0)$ & $0(0)$ & $0(0)$ \\
\hline HER2 status, No. (\%) & & & & & & & & \\
\hline IHC 3+/FISH+ & $66(68.4)$ & $64(65.3)$ & $104(92.9)$ & $103(93.6)$ & $132(100)$ & $131(100)$ & $177(97.8)$ & $179(98.9)$ \\
\hline IHC $2+$ & $32(31.6)$ & $33(34.7)$ & $8(7.1)$ & $7(6.4)$ & $0(0)$ & $0(0)$ & $4(2.2)$ & $3(1.1)$ \\
\hline Hormonal receptor status, & No. $(\%)$ & & & & & & & \\
\hline ER+ & $51(52)$ & $63(64.3)$ & $50(44.6)$ & $39(35.5)$ & NS & NS & NS & NS \\
\hline PgR+ & $40(40.8)$ & $47(48.0)$ & 38 (33.9) & $31(28.2)$ & NS & NS & NS & NS \\
\hline $\mathrm{ER}+/ \mathrm{PgR}+$ & NS & NS & $56(50.0)$ & $45(40.9)$ & $86(62.5)$ & $95(72.5)$ & $75(41.4)$ & $81(44.5)$ \\
\hline Disease involvement, No. & & & & & & & & \\
\hline Visceral & $52(53.1)$ & $39(39.8)$ & NS & NS & $77(58.3)$ & $87(66.4)$ & NS & NS \\
\hline Lung & NS & NS & $26(23.2)$ & $31(28.2)$ & NS & NS & 90 (49.7) & $90(49.5)$ \\
\hline Bone & $42(42.9)$ & $37(37.7)$ & $26(23.2)$ & $28(25.5)$ & $44(33.3)$ & $55(41.9)$ & $64(35.4)$ & $71(39.0)$ \\
\hline Liver & $34(34.7)$ & $42(429)$ & 15 (13.4) & $22(20.0)$ & $65(49.2)$ & $67(51.1)$ & $70(38.7)$ & $80(44.0)$ \\
\hline Soft tissue & $46(46.9)$ & $52(53.1)$ & $32(28.6)$ & $42(38.2)$ & NS & NS & NS & NS \\
\hline Other $^{\mathrm{a}}$ & $9(9.2)$ & $3(3.1)$ & $9(8.0)$ & $10(9.1)$ & NS & NS & $113(62.4)$ & $108(59.3)$ \\
\hline Prior therapy, No. (\%) & & & & & & & & \\
\hline Surgery & 78 (79.6) & $74(75.5)$ & NS & NS & NS & NS & NS & NS \\
\hline Chemotherapy & $48(49.0)$ & $45(45.9)$ & $55(49.1)$ & $55(50.0)$ & $73(55.7)$ & $71(53.8)$ & NS & NS \\
\hline Radiotherapy & $37(37.8)$ & $41(41.8)$ & $49(43.8)$ & $52(47.3)$ & NS & NS & NS & NS \\
\hline Hormonal therapy & $39(40.8)$ & $50(51.0)$ & $35(31.3)$ & $36(32.7)$ & $48(36.4)$ & $35(26.7)$ & NS & NS \\
\hline Anthracycline & NS & NS & $49(43.8)$ & $49(44.5)$ & $43(32.6)$ & $43(32.8)$ & $59(32.6)$ & $60(33.0)$ \\
\hline Taxane & NS & NS & NS & NS & $12(9.1)$ & $14(10.7)$ & $14(7.7)$ & $12(6.6)$ \\
\hline Trastuzumab & NS & NS & NS & NS & NS & NS & $2(1.1)$ & $4(1.1)$ \\
\hline No prior chemotherapy & NS & NS & NS & NS & $59(44.7)$ & $57(43.5)$ & NS & NS \\
\hline Outcomes & & & & & & & & \\
\hline Follow-up (months) & 52 & & 26 (median) & & 84 & & 44 (median) & \\
\hline $\begin{array}{l}\text { Median response dura- } \\
\text { tion (months) }\end{array}$ & 13 & 11 & 15.9 & 13.4 & 10.7 & 9.4 & 18.1 & 15.3 \\
\hline Median OS (months) & 35.7 & 32.2 & 46.0 & 40.2 & 37.4 & 37.1 & 33.6 & 29.0 \\
\hline Median PFS (months) & 10.7 & 7.1 & 17.9 & 12.8 & NR & NR & 16.1 & 14.5 \\
\hline $\begin{array}{l}\text { Primary and secondary } \\
\text { end points }\end{array}$ & PFS, OS, ORR, & CR, Safety & PFS, OS, ORR & CR, Safety & OS, ORR, DCR, Safety & & PFS, OS, OI & CR, Safety \\
\hline
\end{tabular}

$R C T$ randomized clinical trial, ECOG-PS Eastern Cooperative Oncology Group performance status, KPS Karnofsky performance status, $I H C$ immunohistochemistry, FISH fluorescence in situ hybridization, $H E R 2$ human epidermal growth factor receptor 2, $E R$ estrogen receptor, $P g R$ progesterone receptor, $N S$ not specified, $H P C$ trastuzumab, paclitaxel and carboplatin, $H P$ trastuzumab and paclitaxel, $H T X$ trastuzumab, docetaxel and capecitabine, $H T$ trastuzumab and docetaxel, $H T C$ trastuzumab, docetaxel and carboplatin, $H T$ trastuzumab and docetaxel, $H P M$ trastuzumab, paclitaxel and non-pegylated liposomal doxorubicin, $H P$ trastuzumab and paclitaxel, $D O R$ duration of response, $P F S$ progression-free survival, $O S$ overall survival, $O R R$ objective response rate, $D C R$ disease control rate

*Other sites for metastatic disease included the heart, lymph nodes, adrenal glands, kidneys, and chest wall 


\section{(A)}

$\mathrm{H}+\mathrm{D} \mathrm{CT} \quad \mathrm{H}+\mathrm{S} \mathrm{CT}$

Study Events Total Events Total RR 95\%CI

Robert ${ }^{14} 2006$

48

79

$92 \quad 34$

79

$112 \quad 80$

96

80

$94 \quad 1.44$ [1.03 to 2.01$]$

Valero $^{15} 2011$

12

$132 \quad 95$

$\begin{array}{ll}110 & 0.97 \quad[0.82 \text { to } 1.14]\end{array}$

$131 \quad 1.00 \quad[0.86$ to 1.16$]$

$\begin{array}{lll}182 & 1.08 \quad[0.92 \text { to } 1.25]\end{array}$

Heterogeneity: $P^{2}=41.3 \%, \tau^{2}=0.0058, p=0.1642$

Test for overall effect: $p=0.1568$
Valero ${ }^{15} 2011$

\begin{tabular}{llll}
\hline Fixed effect model & 517 & 517 & 1.07
\end{tabular}$\left[\begin{array}{l}0.98 \text { to } 1.17] \\
\hline\end{array}\right.$

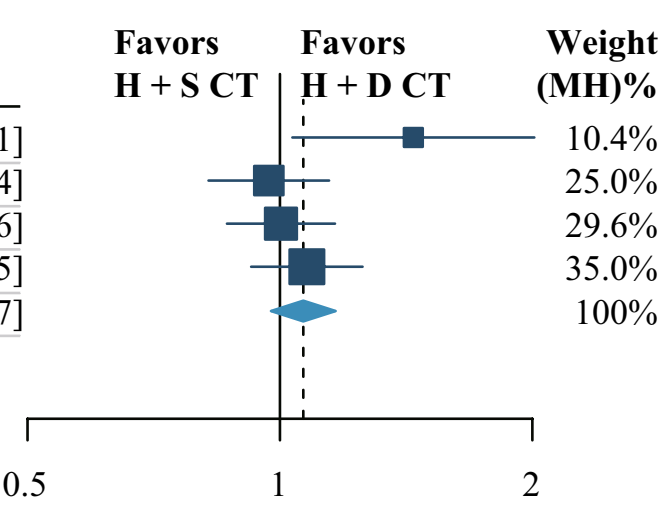

(B)

\begin{tabular}{|c|c|c|c|c|c|c|}
\hline \multirow[b]{2}{*}{ Study } & \multicolumn{2}{|c|}{$\mathbf{H}+\mathbf{D} \mathbf{C T}$} & \multicolumn{2}{|c|}{$\mathbf{H}+\mathbf{S ~ C T}$} & \multirow[b]{2}{*}{$\mathbf{R R}$} & \multirow[b]{2}{*}{$95 \% \mathrm{CI}$} \\
\hline & $\overline{\text { Events }}$ & Total & Events & Total & & \\
\hline Robert $^{14} 2006$ & 83 & 92 & 74 & 94 & 1.15 & [1.01 to 1.30$]$ \\
\hline Wardley $^{24} 2010$ & 107 & 112 & 98 & 110 & 1.07 & {$[0.99$ to 1.16$]$} \\
\hline Valero $^{15} 2011$ & 116 & 132 & 119 & 131 & 0.97 & {$[0.89$ to 1.05$]$} \\
\hline \multicolumn{2}{|c|}{ Random effects model } & 336 & & 335 & 1.05 & {$[0.96$ to 1.15$]$} \\
\hline \multicolumn{7}{|c|}{ Heterogeneity: $I^{2}=65.8 \%, \tau^{2}=0.0042, p=0.0539$} \\
\hline
\end{tabular}

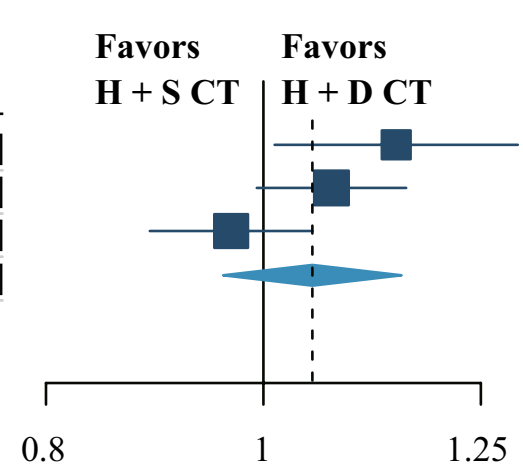

Weight

(DL)\%

$26.3 \%$

$37.8 \%$

$36.0 \%$

$100 \%$

(C)

\begin{tabular}{lllll} 
Study & H + D C T & H + S CT & HR & $\mathbf{9 5 \% C I ~}$ \\
\hline Robert $^{14} 2006$ & 92 & 94 & 0.66 & {$[0.59$ to 0.73$]$} \\
Wardley $^{24} 2010$ & 112 & 110 & 0.72 & {$[0.53$ to 0.98$]$} \\
\hline Baselga $^{25} 2014$ & 181 & 182 & 0.84 & {$[0.65$ to 1.08$]$} \\
\hline Fixed effect model & & & 0.66 & {$[0.63$ to 0.75$]$}
\end{tabular}

Heterogeneity: $I^{2}=31.3 \%, \tau^{2}=0.0056, p=0.2332$

Test for overall effect: $p<0.0001$

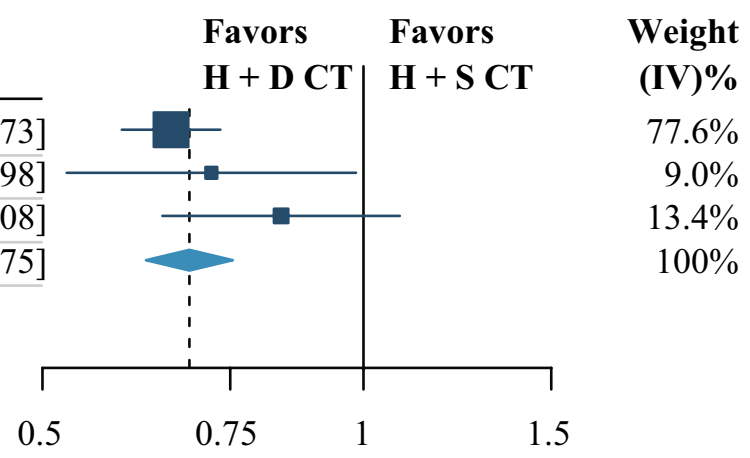

(D)

Weight

$77.6 \%$

$9.0 \%$

$13.4 \%$

$100 \%$

\begin{tabular}{lllll} 
Study & H + D CT & H + S CT & HR & $\mathbf{9 5 \% C I}$ \\
\hline Robert $^{14} 2006$ & 92 & 94 & 0.90 & {$[0.80$ to 0.92$]$} \\
\hline Wardley $^{24} 2010$ & 112 & 110 & 0.86 & {$[0.60$ to 1.24$]$} \\
Valero $^{15} 2011$ & 132 & 131 & 1.01 & {$[0.76$ to 1.35$]$} \\
\hline Baselga $^{25} 2014$ & 181 & 182 & 0.79 & {$[0.61$ to 1.03$]$} \\
\hline Fixed effect model & & & 0.90 & [0.88 to 0.92$]$
\end{tabular}

Heterogeneity: $I^{2}=0 \%, \tau^{2}=0, p=0.6688$

Test for overall effect: $p<0.0001$

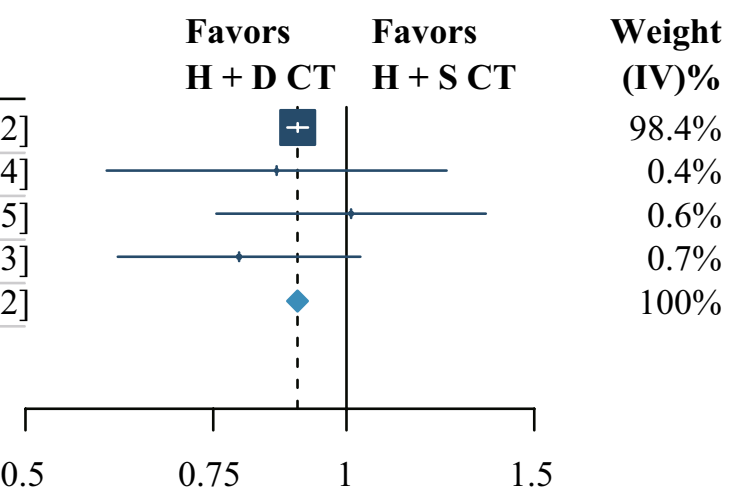

Fig. 1 Forest plot of the a overall response rate, $\mathbf{b}$ disease control rate, $\mathbf{c}$ progression-free survival, and $\mathbf{d}$ overall survival for the two treatment groups. $R R$ risk ratio; $H R$ hazard ratio; $95 \% C I$ 95\% confidence interval; $H$ trastuzumab; $C T$ chemotherapy; $D$ doublet; $S$ single-agent 
Table 2 Efficacies of the two treatments

\begin{tabular}{|c|c|c|c|c|c|c|c|}
\hline \multirow[t]{2}{*}{ Outcomes } & \multirow[t]{2}{*}{ No. of participants } & \multicolumn{3}{|l|}{ Relative effect } & \multirow{2}{*}{$\begin{array}{l}\text { Risk difference } \\
(95 \% \mathrm{CI})\end{array}$} & \multicolumn{2}{|l|}{ GRADE } \\
\hline & & Ratio (95\% CI) & $P$ value & $I^{2}$ & & Quality & Importance \\
\hline Complete response & $671(14,15,24)$ & RR 1.28 (0.90 to 1.82$)$ & 0.176 & $37.5 \%$ & $4 \%(-2$ to $9 \%)$ & $\begin{array}{l}\oplus \oplus \mathrm{OO} \\
\mathrm{Low}^{\mathrm{a}, \mathrm{b}}\end{array}$ & Important \\
\hline Partial response & $671(14,15,24)$ & RR 1.07 (0.83 to 1.38 ) & 0.601 & $61.9 \%$ & $3 \%(-9$ to $16 \%)$ & $\begin{array}{l}\oplus \oplus \mathrm{OO} \\
\text { Low }^{\mathrm{a}, \mathrm{b}}\end{array}$ & Important \\
\hline Overall response & $1034(14,15,24,25)$ & RR 1.07 (0.98 to 1.17 ) & 0.157 & $41.3 \%$ & $4 \%(-2$ to $10 \%)$ & $\begin{array}{l}\oplus \oplus \oplus \mathrm{O} \\
\text { Moderate }^{\mathrm{a}}\end{array}$ & Critical \\
\hline Stable disease & $671(14,15,24)$ & RR 1.02 (0.78 to 1.32$)$ & 0.910 & $40.0 \%$ & $0.4 \%(-6$ to $7 \%)$ & $\begin{array}{l}\oplus \oplus \mathrm{OO} \\
\text { Low }^{\mathrm{a}, \mathrm{b}}\end{array}$ & Important \\
\hline Disease control & $671(14,15,24)$ & RR 1.05 (0.96 to 1.15$)$ & 0.282 & $65.8 \%$ & $5 \%(-4$ to $13 \%)$ & $\begin{array}{l}\oplus \oplus \mathrm{OO} \\
\text { Low }^{\mathrm{a}, \mathrm{c}}\end{array}$ & Important \\
\hline Progressive disease & $671(14,15,24)$ & RR 0.59 (0.34 to 1.04$)$ & 0.066 & $22.1 \%$ & $-5 \%(-11$ to $1 \%)$ & $\begin{array}{l}\oplus \oplus \mathrm{OO} \\
\text { Low }^{\mathrm{a}, \mathrm{b}}\end{array}$ & Important \\
\hline Median duration of response & $1034(14,15,24,25)$ & MR 1.17 (1.10 to 1.25$)$ & $<0.0001$ & $0.0 \%$ & - & $\begin{array}{l}\oplus \oplus \oplus \mathrm{O} \\
\text { Moderate }^{\mathrm{a}}\end{array}$ & Important \\
\hline Progression-free survival & $771(14,24,25)$ & HR 0.69 (0.63 to 0.75$)$ & $<0.0001$ & $31.3 \%$ & - & $\begin{array}{l}\oplus \oplus \oplus \mathrm{O} \\
\text { Moderate }^{\mathrm{a}}\end{array}$ & Critical \\
\hline $\begin{array}{l}\text { Median progression-free } \\
\text { survival }\end{array}$ & $771(14,24,25)$ & MR 1.32 (1.09 to 1.60$)$ & 0.004 & $85.7 \%$ & - & $\begin{array}{l}\oplus \oplus \mathrm{OO} \\
\text { Low }^{\mathrm{a}, \mathrm{c}}\end{array}$ & Important \\
\hline Overall survival & $1034(14,15,24,25)$ & HR 0.90 (0.88 to 0.92$)$ & $<0.0001$ & $0.0 \%$ & - & $\begin{array}{l}\oplus \oplus \oplus \mathrm{O} \\
\text { Moderate }^{\mathrm{a}}\end{array}$ & Critical \\
\hline Median overall survival & $1034(14,15,24,25)$ & MR 1.11 (1.04 to 1.18$)$ & 0.001 & $9.1 \%$ & - & $\begin{array}{l}\oplus \oplus \oplus \mathrm{O} \\
\text { Moderate }^{\mathrm{a}}\end{array}$ & Important \\
\hline
\end{tabular}

$C I$ confidence interval; $H R$ hazard ratio; $R R$ risk ratio; $M R$ median ratio

Grade Working Group grades of evidence

$\oplus \oplus \oplus \oplus$ High quality: further research is very unlikely to change our confidence in the estimated effect

$\oplus \oplus \oplus$ OModerate quality: further research is likely to have an important impact on our confidence in the estimated effect and might change the estimate

$\oplus \oplus$ OOLow quality: further research is very likely to have an important impact on our confidence in the estimated effect and might change the estimate

$\oplus$ OOOVery low quality: we are very uncertain about the estimate

${ }^{a}$ Downgraded $(-1)$ for risk of bias: all trials were judged as having an unclear or high risk of bias related to the blinding of participants and personnel

${ }^{\mathrm{b}}$ Downgraded (-1) for imprecision: small sample bias might exist, or the $95 \%$ confidence intervals are wide; the study includes no effect and fails to exclude important benefits or serious harmful effects

${ }^{c}$ Downgraded $(-1)$ for inconsistency: substantial heterogeneity $\left(I^{2}>50 \%\right)$ was found among the trials

low-quality evidence indicating that the doublet $\mathrm{CT}+\mathrm{H}$ group had a significantly longer PFS than did the single-agent $\mathrm{CT}+\mathrm{H}$ group $(\mathrm{MR}=1.32,95 \%$ CI $1.09-1.60$, $P=0.004, I^{2}=85.7 \%$; Supplementary Fig. S5B, available online). Overall, the results of our meta-analysis provide moderate-quality evidence that doublet $\mathrm{CT}+\mathrm{H}$ is associated with a $31 \%$ reduction in disease-progression risk compared with the disease-progression risk with singleagent $\mathrm{CT}+\mathrm{H}(\mathrm{HR}=0.69,95 \%$ CI $0.63-0.75, P<0.0001$, $I^{2}=31.3 \%$; Fig. 1c, Table 2). The results of Egger's test $(P=0.396)$, Begg's test $(P=1.000)$, and the Copas selection model (Supplementary Fig. S4C, available online) indicated that there was no evidence of publication bias regarding PFS.

\section{Doublet $\mathrm{CT}+\mathrm{H}$ was associated with longer OS}

All four trials (1034 participants) reported comparable median OS values for the doublet $\mathrm{CT}+\mathrm{H}$ and single-agent $\mathrm{CT}+\mathrm{H}$ groups, ranging from 33.6 to 46.0 months and from 29.0 to 40.2 months, respectively. The pooled results provided moderate-quality evidence indicating that the doublet $\mathrm{CT}+\mathrm{H}$ group had a significantly longer OS than the single-agent $\mathrm{CT}+\mathrm{H}$ group $(\mathrm{MR}=1.11,95 \%$ CI $1.04-1.18$, $P=0.001, I^{2}=9.1 \%$; Supplementary Fig. S5C, available online). Overall, the meta-analysis provided moderate-quality evidence showing that in women with HER2-positive $\mathrm{MBC}$, doublet $\mathrm{CT}+\mathrm{H}$ is associated with a $10 \%$ reduction in the risk of death compared with that with single-agent 

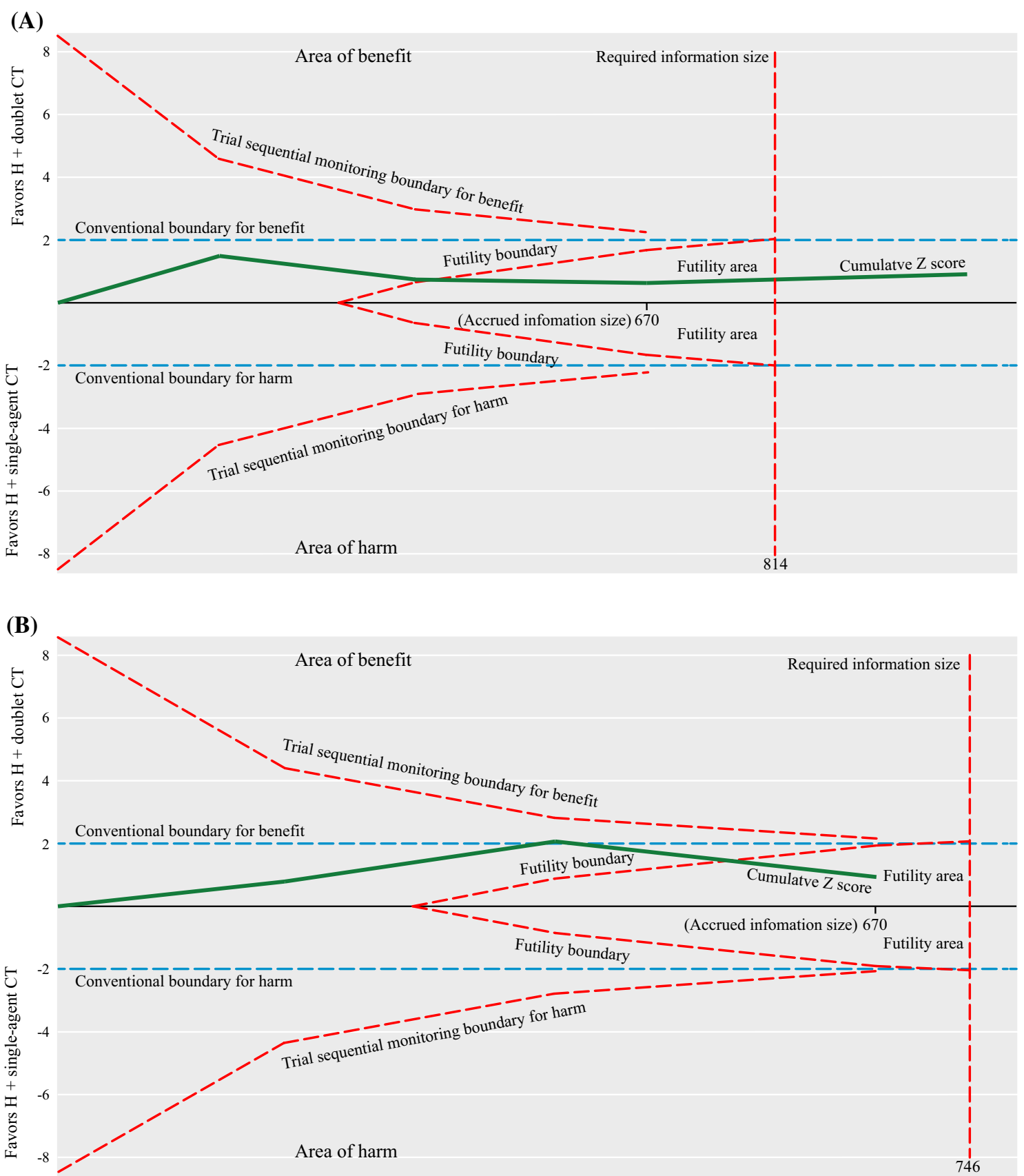

Fig. 2 Trial sequential analysis results for the a overall response rate and $\mathbf{b}$ disease control rate for the two treatment groups. The diversity required information size of 814 (and adjacent trial sequential alpha spending monitoring boundaries) for the objective response rate was calculated based on an $\alpha$ value of 5\% (two-sided), a power of $80 \%$, an anticipated relative risk reduction of $20 \%$, and an event proportion of $62.68 \%$ in the control arm, as estimated using a random effects model. The diversity required information size of 746 (and adjacent trial sequential alpha spending monitoring boundaries) for the disease control rate was calculated based on an $\alpha$ value of 5\% (two-sided), a power of $80 \%$, an anticipated relative risk reduction of $20 \%$, and an event proportion of $86.86 \%$ in the control arm, as estimated using a random effects model. The solid green cumulative $Z$ curves indicate the cumulative $Z$ score from the inverse-variance model $Z$ statistic when a new trial is added. The solid green cumulative $Z$ curves cross the dashed red futility boundary, and trial sequential alpha spending monitoring boundaries represent the objective response rate and disease control rate. The horizontal dotted blue lines illustrate the traditional level of statistical significance $(P=0.05) . H$ trastuzumab; $C T$ chemotherapy 
$\mathrm{CT}+\mathrm{H}\left(\mathrm{HR}=0.90,95 \% \mathrm{CI} 0.88-0.92, P<0.0001, I^{2}=0 \%\right.$; Fig. 1D, Table 2). The results of Egger's test $(P=0.814)$, Begg's test $(P=1.000)$, and the Copas selection model (Supplementary Fig. S4D, available online) indicated that there was no evidence of publication bias regarding OS.

\section{Safety}

For non-hematologic toxicities, the meta-analysis provided moderate-quality evidence showing that compared with single-agent $\mathrm{CT}+\mathrm{H}$, doublet $\mathrm{CT}+\mathrm{H}$ significantly increased the risk of nausea/vomiting $(\mathrm{RR}=4.26, P=0.002$; $\mathrm{NNTH}=25)$, diarrhea $(\mathrm{RR}=2.81, P=0.002 ; \mathrm{NNTH}=25)$, and stomatitis $(\mathrm{RR}=5.02, P=0.003 ; \mathrm{NNTH}=25)$. For hematologic toxicities, the meta-analysis provided moderate-quality evidence indicating that doublet $\mathrm{CT}+\mathrm{H}$ significantly increased the risk of thrombocytopenia $(\mathrm{RR}=4.08$, $P=0.000 ;$ NNTH $=20)$. We also examined whether the potential benefit of doublet $\mathrm{CT}+\mathrm{H}$ was offset by its higher toxicity rate by comparing the benefits (HR) with the risks of grade 3 or 4 thrombocytopenia, stomatitis, nausea/vomiting, and diarrhea (as percentages) between the doublet $\mathrm{CT}+\mathrm{H}$ and single-agent $\mathrm{CT}+\mathrm{H}$ groups (Fig. 3). There was only a slight association between the risk rates for these grade 3 or 4 toxicities and the doublet $\mathrm{CT}+\mathrm{H}$ intervention. The safety results are summarized in Table $\mathrm{S} 2$ in the Supplemental Materials section (available online).

\section{Study withdrawals}

Three trials [14, 24, 25] (781 participants) reported that 89 patients discontinued therapy as a result of treatment-related toxicities. The pooled RR provided very low-quality evidence that revealed no significant difference in the number of patients who discontinued therapy between the doublet $\mathrm{CT}+\mathrm{H}$ and single-agent $\mathrm{CT}+\mathrm{H}$ groups $(10 \%$ vs. $8 \%$, respectively; RR $=1.15,95 \%$ CI $0.50-2.65, P=0.747, I^{2}=53.9 \%$; $\mathrm{RD}=2 \%, 95 \% \mathrm{CI}-5$ to $8 \%$; Supplementary Table S2 and Supplementary Fig. S6A, available online). No publication bias was identified from the results of Egger's test $(P=0.872)$, Begg's test $(P=1.000)$, or the Copas selection model (Supplementary Fig. S4E, available online).
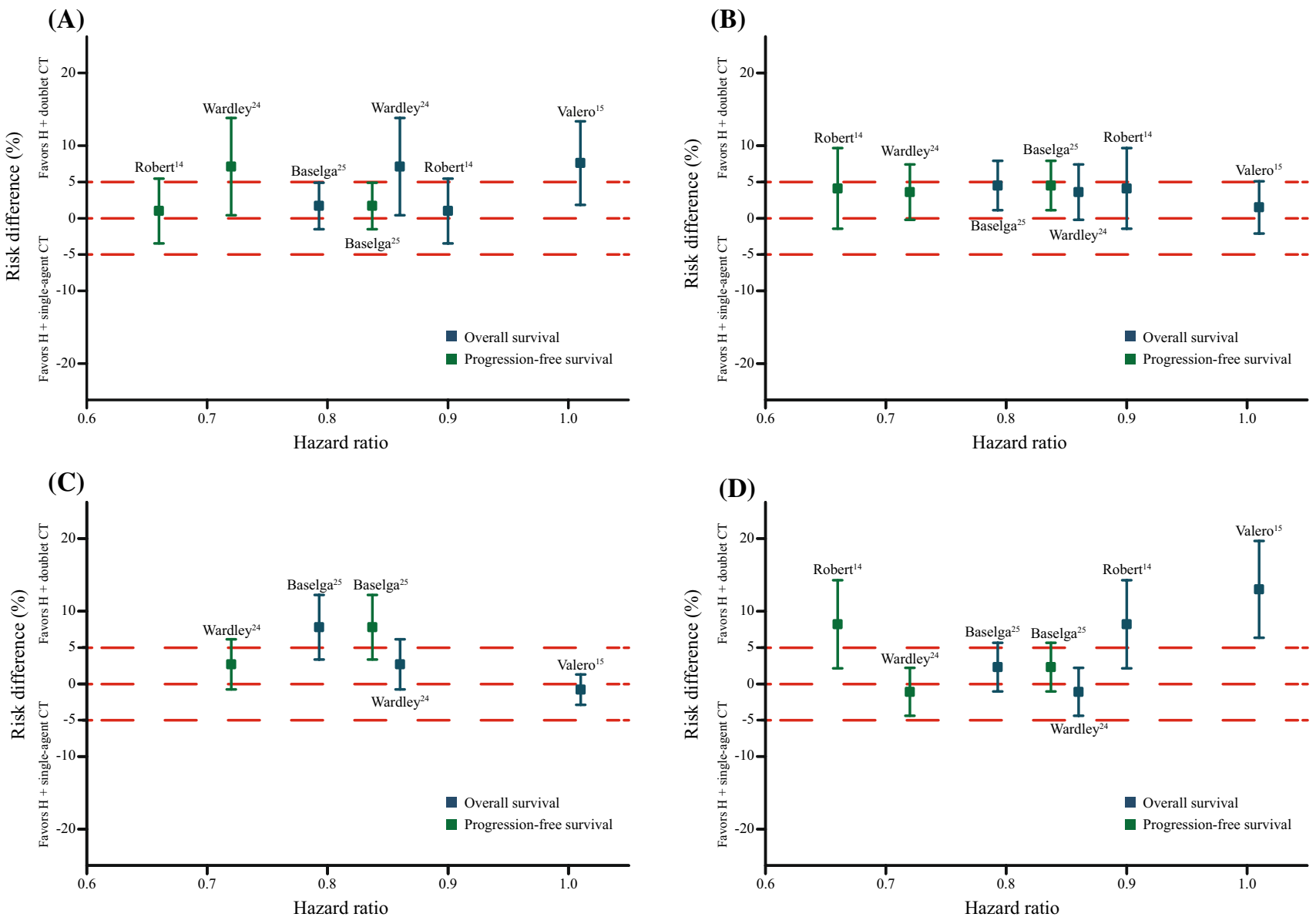

Fig. 3 Effects of the two treatment approaches on absolute grade 3 or 4 toxicities for a diarrhea, $\mathbf{b}$ nausea/vomiting, $\mathbf{c}$ stomatitis, and $\mathbf{d}$ thrombocytopenia 
Three trials [15, 24, 25] (848 participants) reported 27 deaths during the drug therapy period. The pooled incidence of mortality (3\%) was the same for both treatment arms. The pooled RR provided very low-quality evidence showing the absence of a significant difference in mortality between the doublet $\mathrm{CT}+\mathrm{H}$ and single-agent $\mathrm{CT}+\mathrm{H}$ groups $(\mathrm{RR}=0.80$, $95 \%$ CI $0.38-1.68, P=0.557, I^{2}=0.0 \%$; RD $=-1 \%, 95 \%$ CI -3 to $2 \%$; Supplementary Table S2 and Supplementary Fig. S6B, available online). No publication bias was identified from the results of Egger's test $(P=0.993)$, Begg's test $(P=1.000)$, or the Copas selection model (Supplementary Fig. S6F, available online).

\section{Discussion}

\section{Principal findings}

To the best of our knowledge, this study constitutes the first meta-analysis to comprehensively and systematically evaluate the efficacy and safety of single-agent $\mathrm{CT}+\mathrm{H}$ versus doublet $\mathrm{CT}+\mathrm{H}$ as first-line therapy for patients with HER2positive MBC. Our investigation describes the effects of the duration and efficacy of these treatments on survival. Overall, 1044 patients were included, and no significant differences in the ORR (66\% vs. $61 \%, P=0.157)$ or DCR (92\% vs. $87 \%, P=0.282$ ) were found between the groups. PFS $(P<0.0001)$ and OS $(P<0.0001)$ were significantly longer in the doublet $\mathrm{CT}+\mathrm{H}$ group than in the single-agent $\mathrm{CT}+\mathrm{H}$ group, and the results showed a clinically meaningful difference in median survival. The results of safety analyses showed that both groups tolerated the drug regimens well. Fewer grade 3 or 4 adverse events were associated with single-agent $\mathrm{CT}+\mathrm{H}$ than with doublet $\mathrm{CT}+\mathrm{H}$.

\section{Implications for clinical practice}

The current NCCN guidelines recommend pertuzumab plus trastuzumab in combination with a taxane as the preferred first-line therapy for HER2-positive MBC [13, 26]. However, pertuzumab has not yet been approved as a treatment for patients with HER2-positive MBC in several countries, including China. Therefore, first-line trastuzumab in combination with a selected CT regimen (e.g., paclitaxel \pm carboplatin, docetaxel, vinorelbine, and capecitabine) is another therapeutic option for HER2-positive MBC [13]. However, whether doublet CT is superior to single-agent CT in combination with trastuzumab for such patients has not been clarified. The results of a prior literature-based meta-analysis suggested that combination CT results in a better ORR than a sequential single-agent $\mathrm{CT}$ in patients with HER2-negative MBC. However, no difference in OS or PFS was found when these treatment strategies were compared in HER2-positive
MBC [27]. These findings support international guidelines that recommend the use of sequential monotherapy for most cases of $\mathrm{MBC}$, unless rapid disease progression, or life-threatening visceral metastases occurs, or the need for rapid symptom or disease control is present, in which case combination CT is preferred [28]. Nonetheless, whether the most effective chemotherapy regimen should consist of single or doublet chemotherapeutic agents combined with trastuzumab for HER2-positive disease remains unclear.

In the present meta-analysis, although no statistically significant difference in the ORR was found between the groups, doublet $\mathrm{CT}+\mathrm{H}$ resulted in a significantly longer median response duration than single-agent $\mathrm{CT}+\mathrm{H}$ $(\mathrm{MR}=1.17, P<0.0001)$. The PFS and OS were also significantly longer in the doublet $\mathrm{CT}+\mathrm{H}$ group than in the single-agent $\mathrm{CT}+\mathrm{H}$ group. Altogether, these findings indicate that greater inconsistency and fewer direct correlations may exist between the response rate and survival benefits.

One explanation for the differences in PFS and OS but not the ORR between the study arms is that doublet $\mathrm{CT}+\mathrm{H}$ resulted in a prolonged median response duration, which might also underlie the inconsistencies noted between the short-term response and long-term survival benefits. This phenomenon was also observed in other trials. For instance, in the FIRE-3 trial, no significant difference was identified in the ORR of patients with metastatic colorectal cancer when either cetuximab or bevacizumab was added to fluorouracil with folinic acid and irinotecan (FOLFIRI). However, cetuximab was associated with a longer OS, which suggests that FOLFIRI plus cetuximab should be the preferred first-line regimen for these patients [29]. The inconsistencies noted in the abovementioned study might be due to the deepness of response (DpR) to therapy, as the DpR might not have been adequately captured using RECIST guidelines when comparing the different targeted therapies.

Another reason that a significant difference in longterm survival benefit was observed but no apparent difference in the short-term response was found between the groups could be the immunologic effect of the treatment. The mechanisms of action of trastuzumab include the direct arrest of cell growth, the induction of apoptosis, the inhibition of HER 2 shedding, and the recruitment of immune effector cells that mediate tumor cell lysis. The recruitment of immune effector cells and subsequent cell lysis, designated ADCC, depends on the expression of Fc receptors (FcRs) in innate immune cells [30]. A recent study conducted using FinHER adjuvant samples [31] was the first to demonstrate an association between high numbers of tumor-infiltrating lymphocytes and an increased benefit of trastuzumab in HER2+ MBC. Thus, although trastuzumab is thought to act primarily on tumor cells, antitumor immunity might also underlie the efficacy of anti-HER2 treatment. 
Recent data have indicated that both nivolumab and pembrolizumab significantly improved OS but not PFS [32-35], which suggests that a divide exists between response-based endpoints and survival in some settings, even for programmed death 1 (PD-1) inhibitors. Immunotherapeutic agents produce antitumor effects by inducing cancer-specific immune responses or modifying native immune processes. The resulting clinical response patterns extend beyond those of cytotoxic agents and can manifest after an initial increase in the tumor burden or the appearance of new lesions (i.e., disease progression).

Therefore, RECIST or WHO criteria, which are designed to detect early effects of cytotoxic agents, might not provide a complete assessment of immunotherapeutic agents. The modification of these criteria to capture the unique response patterns generated by immunotherapeutic agents has previously been proposed and is becoming increasingly recognized as necessary for the proper evaluation of these agents [36]. In a case study of an ipilimumab-treated patient who exhibited disease progression at a 12-week tumor assessment, histologic analyses indicated that the increase in lesion size likely resulted from $\mathrm{T}$ cell infiltration as opposed to tumor cell proliferation [37]. Thus, inflammation in baseline lesions might be misinterpreted as disease progression (a version of the "tumor flare reaction"). Therefore, for immunotherapeutic agents that induce tumor shrinkage in some patients, the evaluation of immune-related criteria will likely provide a more comprehensive assessment of clinical activity and might help explain why patients with apparent progressive disease experience better long-term survival in some cases.

Improving survival of patients with metastatic disease is a worthy goal, even if objective responses are not improved. Furthermore, evaluating the statistical and clinical significance of intervention outcomes [38] by assessing the magnitudes of effect sizes, patient-reported minimum relevant differences and self-perceived meaningful benefits [39], provides considerable insight into treatment-related toxicity, including grade 3 or 4 hematologic and non-hematologic toxicities, reasons for therapy discontinuation, and mortality during therapy. Moreover, patient performance status should be equally considered when reporting prognostic factors and associated outcomes. Previous studies have demonstrated that patients with a good pre-CT performance status may have a clinically significantly longer OS than expected [24]. The results of our toxicity analysis indicated that nearly all (99\%) of the patients had a pretreatment performance status of at least $80 \%$ or less than 2, based on the KPS or the ECOG-PS score, respectively, and that treatment-related grade 3 or 4 hematologic and non-hematologic toxicities occurred more frequently with doublet $\mathrm{CT}+\mathrm{H}$ than with single-agent $\mathrm{CT}+\mathrm{H}$. However, no significant differences in mortality or discontinued therapy due to treatment-related toxicities were found between the groups. Given that CT is a frontline therapy for HER2-positive MBC in a variety of clinical settings, determining the pretreatment performance status of a patient is essential. Overall, we believe that treatment regimens should be selected in the context of effectiveness, performance status, comorbidities, and toxicity profiles. Our findings support the use of doublet $\mathrm{CT}+\mathrm{H}$ as first-line therapy for patients with HER2-positive disease unless a patient exhibits a poor pretreatment performance status, in which case single-agent $\mathrm{CT}+\mathrm{H}$ will be recommended. Several factors limited our confidence in the effect estimates and CIs in our meta-analysis (Supplementary limitations, available online).

\section{Conclusion}

In conclusion, the results of this meta-analysis indicate that compared with single-agent $\mathrm{CT}+\mathrm{H}$, doublet $\mathrm{CT}+\mathrm{H}$ results in prolonged PFS and OS but more treatment-related toxicities when used as first-line therapy for patients with HER2-positive MBC. Moreover, compared with patients who received single-agent $\mathrm{CT}+\mathrm{H}$, those who received doublet $\mathrm{CT}+\mathrm{H}$ showed a non-significant trend toward improved ORR. Based on our findings, we recommend doublet $\mathrm{CT}+\mathrm{H}$ as first-line therapy for patients with good pretreatment performance status; however, in the case of patients with poor performance status, single-agent $\mathrm{CT}+\mathrm{H}$ is recommended, regardless of the desire to rapidly reduce the tumor burden.

Funding This work was supported by a grant from the Key Laboratory of Malignant Tumor Molecular Mechanism and Translational Medicine of Guangzhou Bureau of Science and Information Technology ([2013]163), a grant from the Key Laboratory of Malignant Tumor Gene Regulation and Target Therapy of Guangdong Higher Education Institutes (KLB09001), grants from the National Natural Science Foundation of China (81372819, 81572596, U1601223), a grant from the Guangdong Science and Technology Department (2015B050501004), the Specialized Research Fund for the Doctoral Program of Higher Education (20120171110075), funding from the Guangzhou Science and Technology Bureau (2014J4100170, 201704020131), and a grant from the Guangdong Natural Science Foundation (2017A030313828).

Open Access This article is distributed under the terms of the Creative Commons Attribution 4.0 International License (http://creativecommons.org/licenses/by/4.0/), which permits unrestricted use, distribution, and reproduction in any medium, provided you give appropriate credit to the original author(s) and the source, provide a link to the Creative Commons license, and indicate if changes were made.

\section{References}

1. Gschwind A, Fischer OM, Ullrich A (2004) The discovery of receptor tyrosine kinases: targets for cancer therapy. Nat Rev Cancer 4:361-370. https://doi.org/10.1038/nrc1360 
2. Slamon DJ, Clark GM, Wong SG, Levin WJ, Ullrich A, McGuire WL (1987) Human breast cancer: correlation of relapse and survival with amplification of the HER-2/neu oncogene. Science 235:177-182. https://doi.org/10.1126/science.3798106

3. Andrulis IL, Bull SB, Blackstein ME, Sutherland D, Mak C, Sidlofsky S, Pritzker KP, Hartwick RW, Hanna W, Lickley L, Wilkinson R, Qizilbash A, Ambus U, Lipa M, Weizel H, Katz A, Baida M, Mariz S, Stoik G, Dacamara P, Strongitharm D, Geddie W, McCready D (1998) Neu/erbB-2 amplification identifies a poor-prognosis group of women with node-negative breast cancer. Toronto Breast Cancer Study Group. J Clin Oncol 16:1340-1349. https://doi.org/10.1200/JCO.1998.16.4.1340

4. Slamon D, Eiermann W, Robert N, Pienkowski T, Martin M, Press M, Mackey J, Glaspy J, Chan A, Pawlicki M, Pinter T, Valero V, Liu MC, Sauter G, von Minckwitz G, Visco F, Bee V, Buyse M, Bendahmane B, Tabah-Fisch I, Lindsay MA, Riva A, Crown J, Breast Cancer International Research Group (2011) Adjuvant trastuzumab in HER2-positive breast cancer. N Engl J Med 365:1273-1283. https://doi.org/10.1056/NEJMoa0910383

5. Olayioye MA, Neve RM, Lane HA, Hynes NE (2000) The ErbB signaling network: receptor heterodimerization in development and cancer. EMBO J 19:3159-3167. https://doi.org/10.1093/ emboj/19.13.3159

6. Yakes FM, Chinratanalab W, Ritter CA, King W, Seelig S, Arteaga CL (2002) Herceptin-induced inhibition of phosphatidylinositol-3 kinase and Akt Is required for antibody-mediated effects on p27, cyclin D1, and antitumor action. Cancer Res 62:4132-4141

7. Cobleigh MA, Vogel CL, Tripathy D, Robert NJ, Scholl S, Fehrenbacher L, Wolter JM, Paton V, Shak S, Lieberman G, Slamon DJ (1999) Multinational study of the efficacy and safety of humanized anti-HER2 monoclonal antibody in women who have HER2overexpressing metastatic breast cancer that has progressed after chemotherapy for metastatic disease. J Clin Oncol 17:2639-2648. https://doi.org/10.1200/JCO.1999.17.9.2639

8. Schrama D, Reisfeld RA, Becker JC (2006) Antibody targeted drugs as cancer therapeutics. Nat Rev Drug Discov 5:147-159. https://doi.org/10.1038/nrd1957

9. Conlin AK, Seidman AD, Bach A, Lake D, Dickler M, D'Andrea G, Traina T, Danso M, Brufsky AM, Saleh M, Clawson A, Hudis CA (2010) Phase II trial of weekly nanoparticle albumin-bound paclitaxel with carboplatin and trastuzumab as first-line therapy for women with HER2-overexpressing metastatic breast cancer. Clin Breast Cancer 10:281-287. https://doi.org/10.3816/ CBC.2010.n.036

10. Slamon DJ, Leyland-Jones B, Shak S, Fuchs H, Paton V, Bajamonde A, Fleming T, Eiermann W, Wolter J, Pegram M, Baselga J, Norton L (2001) Use of chemotherapy plus a monoclonal antibody against HER2 for metastatic breast cancer that overexpresses HER2. N Eng1 J Med 344:783-792. https://doi.org/10.1056/ NEJM200103153441101

11. Pegram MD, Pienkowski T, Northfelt DW, Eiermann W, Patel R, Fumoleau P, Quan E, Crown J, Toppmeyer D, Smylie M, Riva A, Blitz S, Press MF, Reese D, Lindsay MA, Slamon DJ (2004) Results of two open-label, multicenter phase II studies of docetaxel, platinum salts, and trastuzumab in HER2-positive advanced breast cancer. J Natl Cancer Inst 96:759-769. https:// doi.org/10.1093/jnci/djh133

12. Kulhari H, Pooja D, Rompicharla SV, Sistla R, Adams DJ (2015) Biomedical applications of trastuzumab: as a therapeutic agent and a targeting ligand. Med Res Rev 35:849-876. https://doi. org/10.1002/med.21345

13. Gradishar WJ, Anderson BO, Balassanian R, Blair SL, Burstein HJ, Cyr A, Elias AD, Farrar WB, Forero A, Giordano SH, Goetz M, Goldstein LJ, Hudis CA, Isakoff SJ, Marcom PK, Mayer IA, McCormick B, Moran M, Patel SA, Pierce LJ, Reed EC, Salerno KE, Schwartzberg LS, Smith KL, Smith ML, Soliman H, Somlo
G, Telli M, Ward JH, Shead DA, Kumar R (2015) NCCN guidelines insights breast cancer, version 1.2016. J Natl Compr Cancer Netw 13:1475-1485. https://doi.org/10.6004/jnccn.2015.0176

14. Robert N, Leyland-Jones B, Asmar L, Belt R, Ilegbodu D, Loesch D, Raju R, Valentine E, Sayre R, Cobleigh M, Albain K, McCullough C, Fuchs L, Slamon D (2006) Randomized phase III study of trastuzumab, paclitaxel, and carboplatin compared with trastuzumab and paclitaxel in women with HER-2-overexpressing metastatic breast cancer. J Clin Oncol 24:2786-2792. https://doi. org/10.1200/JCO.2005.04.1764

15. Valero V, Forbes J, Pegram MD, Pienkowski T, Eiermann W, von Minckwitz G, Roche H, Martin M, Crown J, Mackey JR, Fumoleau P, Rolski J, Mrsic-Krmpotic Z, Jagiello-Gruszfeld A, Riva A, Buyse M, Taupin H, Sauter G, Press MF, Slamon DJ (2011) Multicenter phase III randomized trial comparing docetaxel and trastuzumab with docetaxel, carboplatin, and trastuzumab as first-line chemotherapy for patients with HER2-gene-amplified metastatic breast cancer (BCIRG 007 study): two highly active therapeutic regimens. J Clin Oncol 29:149-156. https://doi.org/10.1200/ JCO.2010.28.6450

16. Higgins JPT, Green S (2011) Cochrane handbook for systematic reviews of interventions, version 5.1.0. Cochrane Collaboration. Retrieved from citeulike-article-id: 10329727

17. Liberati A, Altman DG, Tetzlaff J, Mulrow C, Gøtzsche PC, Ioannidis JP, Clarke M, Devereaux PJ, Kleijnen J, Moher D (2009) The PRISMA statement for reporting systematic reviews and metaanalyses of studies that evaluate healthcare interventions: explanation and elaboration. BMJ 339:b2700. https://doi.org/10.1136/ bmj.b2700

18. DerSimonian R, Laird N (1986) Meta-analysis in clinical trials. Control Clin Trials 7:177-188. https://doi. org/10.1016/0197-2456(86)90046-2

19. Mantel N, Haenszel W (1959) Statistical aspects of the analysis of data from retrospective studies of disease. J Natl Cancer Inst 22:719-748

20. Tierney JF, Stewart LA, Ghersi D, Burdett S, Sydes MR (2007) Practical methods for incorporating summary timeto-event data into meta-analysis. Trials 8:16. https://doi. org/10.1186/1745-6215-8-16

21. Copas JB, Shi JQ (2001) A sensitivity analysis for publication bias in systematic reviews. Stat Methods Med Res 10:251-265. https:// doi.org/10.1177/096228020101000402

22. Begg CB, Mazumdar M (1994) Operating characteristics of a rank correlation test for publication bias. Biometrics 50:1088-1101. https://doi.org/10.2307/2533446

23. Egger M, Davey Smith GD, Schneider M, Minder C (1997) Bias in meta-analysis detected by a simple, graphical test. BMJ 315:629634. https://doi.org/10.1136/bmj.315.7109.629

24. Wardley AM, Pivot X, Morales-Vasquez F, Zetina LM, de Fátima Dias Gaui M, Reyes DO, Jassem J, Barton C, Button P, Hersberger V, Torres AA (2010) Randomized phase II trial of firstline trastuzumab plus docetaxel and capecitabine compared with trastuzumab plus docetaxel in HER2-positive metastatic breast cancer. J Clin Oncol 28:976-983. https://doi.org/10.1200/ JCO.2008.21.6531

25. Baselga J, Manikhas A, Cortés J, Llombart A, Roman L, Semiglazov VF, Byakhov M, Lokanatha D, Forenza S, Goldfarb RH, Matera J, Azarnia N, Hudis CA, Rozencweig M (2014) Phase III trial of nonpegylated liposomal doxorubicin in combination with trastuzumab and paclitaxel in HER2-positive metastatic breast cancer. Ann Oncol 25:592-598. https://doi.org/10.1093/annonc/ mdt543

26. Swain SM, Baselga J, Kim SB, Ro J, Semiglazov V, Campone M, Ciruelos E, Ferrero JM, Schneeweiss A, Heeson S, Clark E, Ross G, Benyunes MC, Cortés J, CLEOPATRA Study Group (2015) Pertuzumab, trastuzumab, and docetaxel in HER2-positive 
metastatic breast cancer. N Engl J Med 372:724-734. https://doi. org/10.1056/NEJMoa1413513

27. Dear RF, McGeechan K, Jenkins MC, Barratt A, Tattersall MH, Wilcken N (2013) Combination versus sequential single agent chemotherapy for metastatic breast cancer. Cochrane Database Syst Rev 12:CD008792. https://doi.org/10.1002/14651858. CD008792.pub2

28. Cardoso F, Costa A, Norton L, Cameron D, Cufer T, Fallowfield L, Francis P, Gligorov J, Kyriakides S, Lin N, Pagani O, Senkus E, Thomssen C, Aapro M, Bergh J, Di Leo A, El Saghir N, Ganz PA, Gelmon K, Goldhirsch A, Harbeck N, Houssami N, Hudis C, Kaufman B, Leadbeater M, Mayer M, Rodger A, Rugo H, Sacchini V, Sledge G, van't Veer L, Viale G, Krop I, Winer E (2012) 1st International consensus guidelines for advanced breast cancer (ABC 1). Breast 21:242-252. https://doi.org/10.1016/j. breast.2012.03.003

29. Heinemann V, von Weikersthal LF, Decker T, Kiani A, VehlingKaiser U, Al-Batran SE, Heintges T, Lerchenmüller C, Kahl C, Seipelt G, Kullmann F, Stauch M, Scheithauer W, Hielscher J, Scholz M, Müller S, Link H, Niederle N, Rost A, Höffkes HG, Moehler M, Lindig RU, Modest DP, Rossius L, Kirchner T, Jung A, Stintzing S (2014) FOLFIRI plus cetuximab versus FOLFIRI plus bevacizumab as first-line treatment for patients with metastatic colorectal cancer (FIRE-3): a randomised, open-label, phase 3 trial. Lancet Oncol 15:1065-1075. https://doi.org/10.1016/ S1470-2045(14)70330-4

30. Duong MN, Cleret A, Matera EL, Chettab K, Mathé D, ValsesiaWittmann S, Clémenceau B, Dumontet C (2015) Adipose cells promote resistance of breast cancer cells to trastuzumab-mediated antibody-dependent cellular cytotoxicity. Breast Cancer Res 17:57. https://doi.org/10.1186/s13058-015-0569-0

31. Loi S, Michiels S, Salgado R, Sirtaine N, Jose V, Fumagalli D, Kellokumpu-Lehtinen PL, Bono P, Kataja V, Desmedt C, Piccart MJ, Loibl S, Denkert C, Smyth MJ, Joensuu H, Sotiriou C (2014) Tumor infiltrating lymphocytes are prognostic in triple negative breast cancer and predictive for trastuzumab benefit in early breast cancer: results from the FinHER trial. Ann Oncol 25:1544-1550. https://doi.org/10.1093/annonc/mdu112

32. Borghaei H, Paz-Ares L, Horn L, Spigel DR, Steins M, Ready NE, Chow LQ, Vokes EE, Felip E, Holgado E, Barlesi F, Kohlhäufl M, Arrieta O, Burgio MA, Fayette J, Lena H, Poddubskaya E, Gerber
DE, Gettinger SN, Rudin CM, Rizvi N, Crinò L, Blumenschein GR, Antonia SJ, Dorange C, Harbison CT, Graf Finckenstein F, Brahmer JR (2015) Nivolumab versus docetaxel in advanced nonsquamous non-small-cell lung cancer. N Engl J Med 373:16271639. https://doi.org/10.1056/NEJMoa1507643

33. Motzer RJ, Escudier B, McDermott DF, George S, Hammers HJ, Srinivas S, Tykodi SS, Sosman JA, Procopio G, Plimack ER, Castellano D, Choueiri TK, Gurney H, Donskov F, Bono P, Wagstaff J, Gauler TC, Ueda T, Tomita Y, Schutz FA, Kollmannsberger C, Larkin J, Ravaud A, Simon JS, Xu LA, Waxman IM, Sharma P, CheckMate 025 Investigators (2015) Nivolumab versus everolimus in advanced renal-cell carcinoma. N Engl J Med 373:18031813. https://doi.org/10.1056/NEJMoa1510665

34. Herbst RS, Baas P, Kim DW, Felip E, Pérez-Gracia JL, Han JY, Molina J, Kim JH, Arvis CD, Ahn MJ, Majem M, Fidler MJ, de Castro G, Garrido M, Lubiniecki GM, Shentu Y, Im E, DolledFilhart M, Garon EB (2016) Pembrolizumab versus docetaxel for previously treated, PD-L1-positive, advanced non-small-cell lung cancer (KEYNOTE-010): a randomised controlled trial. Lancet 387:1540-1550. https://doi.org/10.1016/S0140-6736(15)01281-7

35. Hoos A (2016) Development of immuno-oncology drugs-from CTLA4 to PD1 to the next generations. Nat Rev Drug Discov 15:235-247. https://doi.org/10.1038/nrd.2015.35

36. Tuma RS (2008) New response criteria proposed for immunotherapies. J Natl Cancer Inst 100:1280-1281. https://doi.org/10.1093/ jnci/djn334

37. Wolchok JD, Hoos A, O’Day S, Weber JS, Hamid O, Lebbé C, Maio M, Binder M, Bohnsack O, Nichol G, Humphrey R, Hodi FS (2009) Guidelines for the evaluation of immune therapy activity in solid tumors: immune-related response criteria. Clin Cancer Res 15:7412-7420. https://doi.org/10.1158/1078-0432.CCR-09-1624

38. Jakobsen JC, Wetterslev J, Winkel P, Lange T, Gluud C (2014) Thresholds for statistical and clinical significance in systematic reviews with meta-analytic methods. BMC Med Res Methodol 14:120. https://doi.org/10.1186/1471-2288-14-120

39. Jakobsen JC, Gluud C, Winkel P, Lange T, Wetterslev J (2014) The thresholds for statistical and clinical significance-a fivestep procedure for evaluation of intervention effects in randomised clinical trials. BMC Med Res Methodol 14:34. https:// doi.org/10.1186/1471-2288-14-34 